\title{
Malignant angioendotheliosis involving the nervous system: support for a lymphoid origin of the neoplastic cells
}

\author{
S E DANIEL, P RUDGE, * F SCARAVILLI
}

From the Departments of Neuropathology and Neurology,* Institute of Neurology and the National Hospital for Nervous Diseases, London, UK

SUMMARY The clinical and post mortem findings of a case of malignant angioendotheliosis are described. The patient presented with neurological signs attributable to repeated episodes of cerebral and spinal cord infarction. Histological examination showed multifocal intravascular proliferation of mononuclear cells. Immunocytochemical characterisation of these neoplastic cells supports the recent suggestion that this disease represents an unusual form of intravascular lymphoma, which appears to show a predilection for blood vessels of the nervous system.

Malignant angioendotheliosis is a rare condition in which there is partial or complete occlusion of blood vessels by neoplastic cells. These cells show no preferential distribution to a particular calibre of vessel and are found in arterial, venous and capillary lumina. In the original description of this disease ${ }^{1}$ blood vessels of the skin only were involved, but subsequent reports have established the occurrence of widespread vascular involvement of organs and a predilection of the neoplastic cells for the vasculature of the central nervous system. ${ }^{2-4}$

Clinically, patients commonly present with a variety of neurological signs. ${ }^{56}$ In a review of 40 cases Wick et $^{7} \mathrm{l}^{7}$ found that the mean age of onset was 51 years with the sexes equally affected. There was an average survival period of 13 months from the time of presentation and a mortality rate higher than $80 \%$.

The precise histogenesis of the neoplastic cell in this condition remains uncertain and until recently the consensus of opinion, formed on the basis of light and electron microscopy and immunocytochemistry, favoured an endothelial cell origin. ${ }^{38}$ Other investigators have suggested that the disease represents vascular dissemination of an occult carcinoma. ${ }^{9}$ Recently there have been a few reports ${ }^{10-13}$ in which the neoplastic cells were found to exhibit lymphocyte

Address for reprint requests: Dr S E Daniel, Department of Neuropathology, Institute of Neurology, The National Hospital for Nervous Diseases, Queen Square, London WCIN 3BG, UK.

Received 18 November 1986.

Accepted 16 December 1986 cell surface markers suggesting that this condition is a form of intravascular lymphoma.

We describe the clinical course and post mortem findings of a patient with malignant angioendotheliosis in whom the immunocytochemical results lend further support to the hypothesis that this neoplasm is of lymphocytic rather than endothelial cell origin.

\section{Case report}

A 59 year old engineer with no significant past history was found unconscious in his car; within a few minutes he regained consciousness. On admission to hospital he was dysphasic and had right sided hyperreflexia with an extensor plantar response and impaired pain and temperature sense in the right leg. General examination was normal. A complete recovery was made within a few hours. Four days later he had a convulsion following which there was paralysis and paraesthesiae of the right foot. Over the next 7 days the right leg developed a progressive pyramidal type weakness and the left leg became weak. Examination 5 weeks after admission showed paraparesis more severe on the right side, with areflexia and absent plantar responses. The glutei were wasted and weak. Appreciation of pain and temperature was lost in both feet and over the buttocks and vibration could only be felt above the iliac crests. On the sixth week of admission the patient had a pulmonary embolus and was given anticoagulants. The paraparesis became more severe and the appreciation of pain, temperature, position and vibration was lost in both legs; there was also loss of bladder and bowel function. Two months after the initial presentation the patient was quadriplegic with a complete sensory level at D4. Deterioration continued with transient periods of global dysphasia, paraesthesiae in fingers of both 


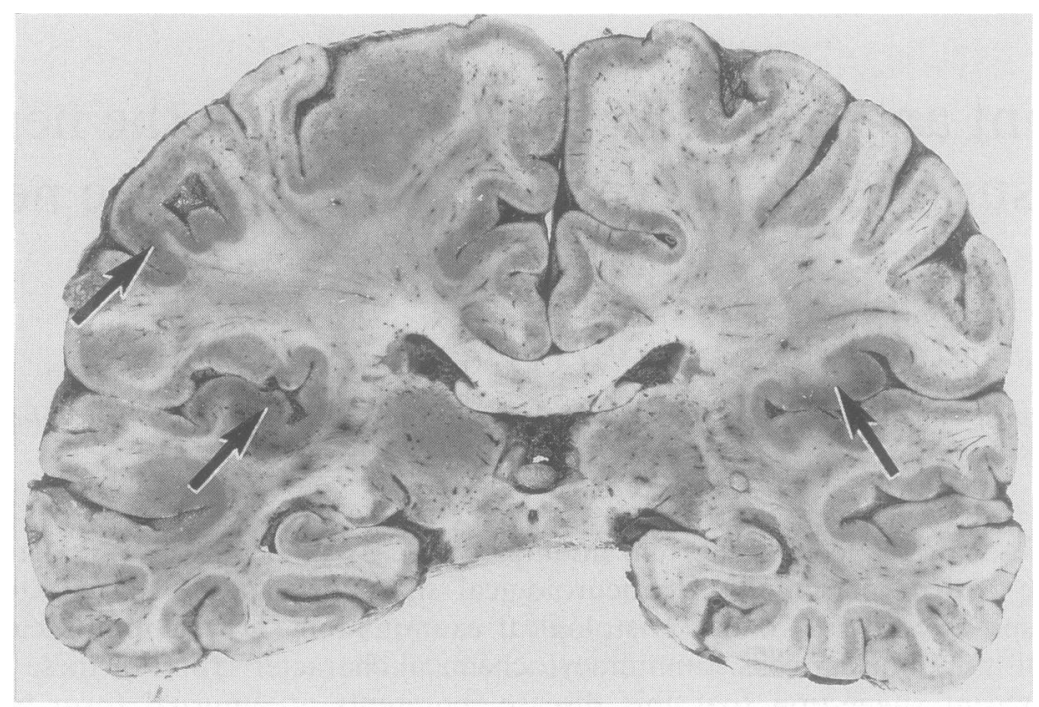

Fig 1 Coronal slice of the brain at the level of the posterior thalamus. Several areas of cortical infarction are present (arrows). Elsewhere blood vessels appear prominent.

hands and weakness of arm and shoulder muscles. The patient was transferred to the National Hospital for Nervous Diseases 14 weeks after the onset of symptoms.

On examination mentation and the cranial nerves were normal. In the arms tone was normal but the left triceps was weak and all the upper limb tendon reflexes were exaggerated. Joint position sense and two point discrimination were absent in the fingers of both hands. There was an areflexic flaccid paraplegia with weakness of the abdominal muscles and loss of sensation below D2 on the right and D3 on the left. The patient died suddenly 4 days later after an illness which had lasted just over 3 months.

Several computed $x$-ray tomographic (CT) scans of the brain, two myelograms and many chest radiographs were normal. Eight weeks after admission a magnetic resonance image (MRI) showed a small area of increased signal on spin echo sequences in the left temporal cortex. Lung scans confirmed the presence of multiple pulmonary infarcts. EMG and nerve conduction studies 1 month after his first presentation showed evidence of bilateral denervation in extensor digitorum brevis and a small sural sensory action potential on the right. Prior to death there was absence of sensory action potentials in ulnar and radial nerves and no motor nerve conduction in the popliteal nerves. All haematological investigations were normal. In the blood biochemistry the only abnormalities were an elevated liver SGOT and SGPT; liver biopsy showed some infiltration of portal tracts by lymphocytes. The CSF was examined on four occasions: at 3 weeks the protein content was $0.8 \mathrm{~g} / 1$ and by 14 weeks had risen to $2 \cdot 2 \mathrm{~g} / 1$, oligoclonal bands were detected on electrophoresis. The cell count ranged from 1-20 lymphocytes $/ \mathrm{mm}^{3}$ and cytology showed no abnormal cells.

\section{Pathological findings}

At necropsy performed 24 hours after death massive pulmonary thrombo-embolism was found occluding the main pulmonary arteries, with recent haemorrhagic infarcts in thष्ठ right middle lobe and both lower lobes. There was throme bosis in the deep calf veins of the left leg. Other finding included changes associated with acute congestive cardia $\vec{\Phi}$ failure. There was no lymphadenopathy and the spleen an\& $\vec{\oplus}$ bone marrow appeared normal.

\section{Neuropathological findings}

The brain weighed $1500 \mathrm{~g}$ and was externally normal. The leptomeningeal blood vessels were slightly congested. Cor nal slices (fig 1) showed multiple small foci of dusky-pin $\vec{k}$ discolouration of the cerebral cortex especially in the depths of sulci in cingular, medial orbito-frontal, and superior temporal gyri. Elsewhere, throughout the grey and white matter, blood vessels appeared congested.

The external appearance of the spinal cord, spinal vessels, and leptomeninges were normal above the lower thoracic region. Below this level the pial surface of the spinal cord was irregular and blood vessels were prominent. Transverse cuts at cervical and thoracic levels showed chalky-white gracile fasciculi against an otherwise normal-looking cord. From $\mathrm{Ll}$ to $\mathrm{S} 5$ the usual internal architecture of the spinal cord was lost; there was no clear demarcation between central grey and peripheral white matter and the posterior columns were soft and brown.

Cervical and thoracic spinal nerve roots were normal, but at lumbar and sacral levels and in the cauda equina, many of the anterior and posterior roots were thin and grey. Posterior root ganglia appeared normal.

After fixation, blocks were taken from many regions of cerebral and cerebellar hemispheres, brain stem, spinal cord, sensory and autonomic ganglia, peripheral nerves and mus- $D$ cles, and embedded in paraffin wax. Sections were stained with haematoxylin-eosin (HE), haematoxylin-van Gieson $\bar{N}$ Miller's stain for elastic tissue, periodic acid-Schiff with and $\Omega$ without diastase predigestion, Picro-Mallory and Martius $N$ 


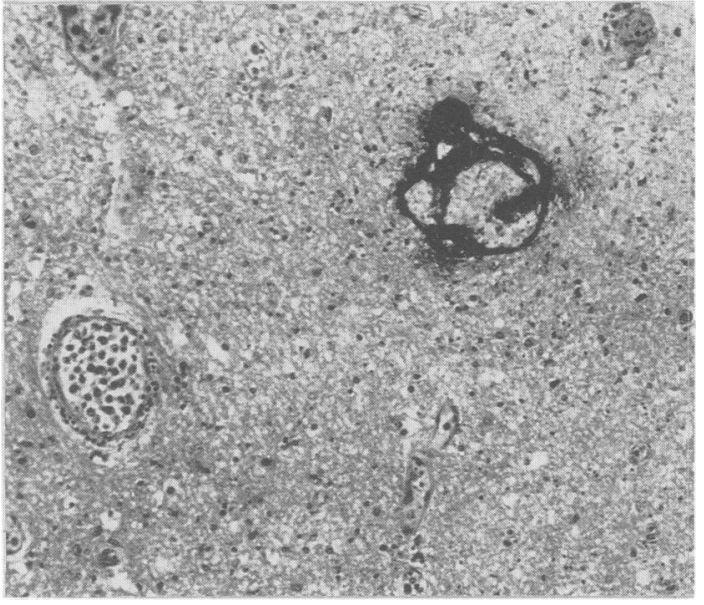

Fig $2 A$ small intracerebral blood vessel shows fibrinoid necrosis in an area of infarction. Intraluminal tumour cells are present in another small vessel. Picro-Mallory, $\times 90$.

scarlet blue trichrome, luxol fast blue-cresyl violet and Glees and Marsland's silver impregnation for axons.

The following antigens were looked for using the peroxidase-antiperoxidase immunocytochemical technique on paraffin-embedded tissue: epithelial membrane antigen, S-100 protein, Ulex europaeus-1 lectin, factor VIII-related antigen, leucocyte common antigen, macrophage, T- and Bcell specific markers, and immunoglobulin (Ig) heavy chains, $\alpha, \gamma$, and $\mu$, and light chains $\kappa$ and $\lambda$. Enzyme histochemistry for chloroacetate esterase was also used.

Sections of blocks taken from tissues other than the nervous system were stained with haematoxylin-eosin and haematoxylin van-Giesen.

For electron microscopy formalin fixed tissue from the spinal leptomeninges was post-fixed in $1 \%$ osmium tetroxide for 3 hours. After dehydration through graded alcohols and embedding in Araldite, $1 \mu \mathrm{m}$ sections were stained with toluidine-blue. Areas rich in blood vessels were selected for

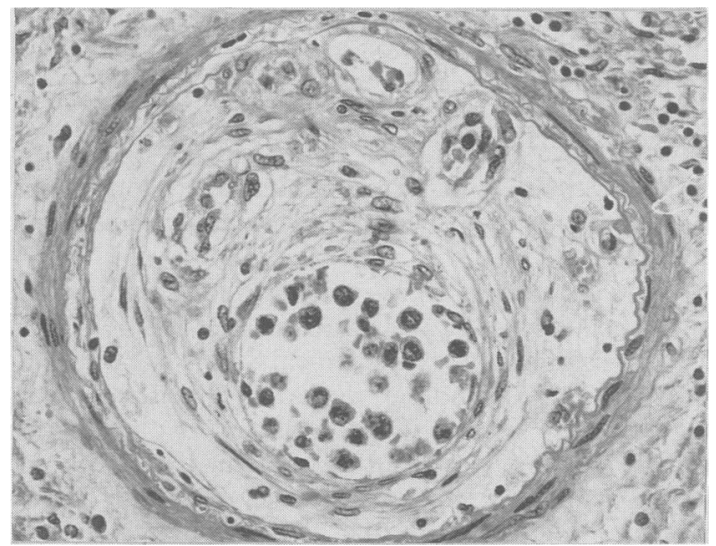

Fig 3 This posterior spinal artery contains tumour cells and show's evidence of recanalisation. Picro-Mallory, $\times 275$. ultrathin sections $(60 \mathrm{~nm})$ and stained with uranyl acetate and lead citrate.

Histological examination of central and peripheral nervous systems showed meningeal and parenchymal blood vessels of varying size filled with pleomorphic malignant cells (figs 2,3 ). The cells had scant amounts of cytoplasm and oval hyperchromatic nuclei that were frequently indented or grooved, with several small nucleoli. Numerous mitoses were seen. In many instances tumour cells appeared to occlude the lumen of vessels and were focally adherent to the endothelium which was flat and showed no evidence of atypia or pleomorphism. Occasionally a few tumour cells lay perivascularly, although migration through vessel walls was not seen. Some blood vessels, both with and without neoplastic cells in their lumina, were cuffed by a thin mantle of mature lymphocytes. Neoplastic cells were not strictly localised to the vasculature of the nervous system and filled blood vessels of perineurial adipose and fibrous connective tissues.

In the brain there were multiple small infarcts involving the cerebral cortex and white matter, which were of varying age ranging from a few days to several weeks. Many small calibre arterioles and venules in areas of necrosis showed fibrinoid necrosis of their walls (fig 2), and occlusion by fibrin thrombi which were in different stages of organisation and sometimes contained tumour cells.

Apart from the content of blood vessels no abnormalities were seen in the hypothalamus, thalamus, basal ganglia, cerebellum, midbrain or pons. In the medulla the gracile nucleus bilaterally showed some depletion of nerve cells with astrocytic and microglial hyperplasia.

In lumbar and sacral regions of the spinal cord there was acute and chronic infarction largely confined to the posterior horns and columns, with less marked ischaemic change of the lateral columns and anterior horns. The degeneration was most severe at $\mathrm{Ll}$; at this level the posterior white matter and horns were partly cystic and surrounded by a rim of gliosis with neovascularisation, the lateral columns showed axonal depletion and contained foamy macrophages while the anterior horns were loose and oedematous with chromatolytic nerve cells.

There was Wallerian degeneration of thoracic and cervical gracile fasciculi. At about D5 localised small areas of ischaemia were seen in the left lateral corticospinal tract and right posterior spinocerebellar tract; above and below this level corresponding ascending and descending tract degeneration was present. Nerve cells of thoracic and cervical levels, although occasionally chromatolytic, were well preserved in number.

Throughout the whole length of the spinal cord many of the blood vessels in addition to containing neoplastic cells were of abnormal morphology; multiple radicular arteries showed evidence of thrombotic occlusion with recanalisation, and at lumbar levels these changes were also seen in the anterior sulcal and posterior spinal arteries and anterior median spinal vein (fig 3 ). In areas of ischaemic infarction there was fibrinoid necrosis of small blood vessel walls.

Many anterior and posterior spinal nerve roots close to the cord and in the cauda equina showed ischaemic change with loss of axons. Several nerve roots and peripheral nerves contained recanalised blood vessels. Occasional nerve cells in the posterior root ganglia were chromatolytic and there were interstitial and perivascular lymphocytic clusters. In 


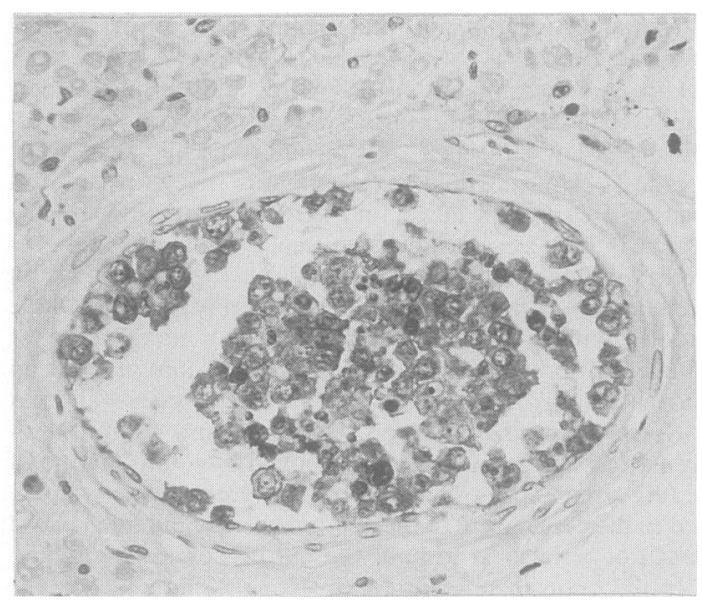

Fig 4 Immunoperoxidase staining for leucocyte common antigen. The malignant intraluminal cells show strong immunoreactivity for this antigen $\times 275$.

the sympathetic superior cervical and coeliac ganglia blood vessels contained the tumour cells. There were small lymphocytic aggregates and increased numbers of Nageotte nodules. Ganglion cells of Auerbach's and Meissner's plexus were normal.

Enzyme histochemistry for chloroacetate esterase of the tumour cells in spinal vessels was negative. With the immunocytochemical stains the cells showed strong immunoreactivity with membrane staining for leucocyte common antigen (fig 4) and were negative for all remaining cell markers.

Although fixation was not optimum, electron microscopy of the neoplastic cells showed no distinguishing characteristics to suggest an endothelial origin; there were no WeibelPalade bodies or intercellular junctions.

In skeletal muscles, perimysial and epimysial blood vessels contained the abnormal cells which were also seen, together with mature lymphocytes, in the immediately subjacent connective tissues. Tibialis anterior and pectoralis major muscles showed chronic partial motor denervation.

Blood vessels of the anterior pituitary, thyroid, parathyroid, testis, prostate and kidney, and the sinusoids of the adrenal gland contained tumour cells. The vasculature of

Table Intravascular distribution of neoplastic cells in organs and nervous tissue

\begin{tabular}{llll}
\hline Heart & 0 & Lymph node & 0 \\
Lung & 0 & Bone marrow & 0 \\
GIT & 0 & Blood film & 0 \\
Liver & 0 & Pachymeninges & +++ \\
Pancreas & 0 & Brain & +++ \\
Kidney & +++ & Spinal cord & +++ \\
Prostate & ++ & Spinal nerve roots & ++ \\
Testis & + & Posterior root ganglia & + \\
Thyroid & + & Autonomic ganglia & ++ \\
Adrenal & ++ & Peripheral nerve & ++ \\
Spleen & 0 & Skeletal muscle & ++ \\
\hline
\end{tabular}

$0=$ no intravascular neoplastic cells; $+=$ few,$+=$ many, $+++=$ numerous intravascular neoplastic cells. remaining general organs and fibrin thrombo-emboli in pulmonary arteries and arterioles were free of tumour cells. There was no abnormality of lymphoid tissue or vertebral bone marrow (table).

\section{Discussion}

This patient is typical of many of those with malignant angioendotheliosis in that the diagnosis was not made during life. Transient cerebral episodes and progressive spinal cord involvement are frequent clinical features of the disorder, but fits, preserved intellect and spinal root damage which our patient also had are unusual. Cutaneous vascular involvement with indurated erythematous plaques characteristically occur in this disease ${ }^{114}$ and histology of these lesions can be diagnostic, but the patient we report had no skin lesions.

The post mortem diagnosis of malignant angioendotheliosis was made on the basis of intravascular neoplastic mononuclear cells in the absence of any evidence of a leukaemia or lymphoma. With immunocytochemical stains the malignant cells stained exclusively for leucocyte common antigen. This surface membrane antigen represents a family of molecules that are found in all human white cells. Lymo phocytes stain most strongly with anti-leucocytê common antigen while monocyte-macrophages, gran 은 ulocytes and plasma cells stain weakly or not at all. ${ }^{1}$ 色 Positive staining of the intraluminal cells for this antio $(D)$ gen and the absence of staining for macrophages ang endothelial cell markers and with chloroacetate estero ase, indicate that they are of haemopoeitic origin an most probably lymphoid. These findings are accordance with recent reports ${ }^{11-131617}$ which sug- $\vec{\oplus}$ gest that malignant angioendotheliosis, rather than a $\stackrel{\infty}{v}$ neoplasm of endothelial cells, is a form of angiotropic or intravascular lymphoma.

In the literature there are a few cases described in which there was both malignant angioendotheliosis and a lymphoma ${ }^{1418}$ and it has been emphasised that the occurrence of these two diseases in the same patient may be related rather than coincidental. ${ }^{1920}$ However, the majority of patients with malignant angioendotheliosis have no evidence of lymphoma and the source of the neoplastic lymphocytes remains uncertain.

The neoplastic cells have been found to express Bcell associated antigens in three cases, ${ }^{11}{ }^{13}$ and in a further case immunocytochemical stains suggested a T-cell origin. ${ }^{13}$ Another report ${ }^{20}$ described dual expression of $\mathrm{T}$ - and B-cell markers by the intraluminal neoplastic cells. In our patient the lymphoid cells appeared to show neither T- or B-cell differentiation. Therefore, results so far indicate that a range of lymphocyte phenotype is probably implicated. 


\section{Malignant angioendotheliosis}

At present the reason for intravascular localisation of the neoplastic cells is not known with certainty; Sheibani et al ${ }^{13}$ suggested that lymphocyte-endothelial cell homing may play a crucial role, alternatively these cells could lack the necessary surface receptors for extravascular migration. ${ }^{12}$

In this patient, vasculature of the central and peripheral nervous systems were both equally severely affected and occlusion of these blood vessels was responsible for the clinical symptoms. Small cerebral cortical infarcts occurred in all the vascular territories. Despite the widespread occlusion and recanalisation of spinal cord blood vessels, the area of infarction was limited to lumbar level in the territory of the posterior spinal arteries. This localisation of ischaemic change reflects the considerable reserves of the anterior spinal artery and venous system of the spinal cord. ${ }^{21}$

Why the neoplastic cell shows a preferential distribution to blood vessels of the nervous system is not known. It has been suggested ${ }^{3}$ that the tumour cell could have originated from this site, but as the lymphocytic nature of this cell is now established this view is no longer tenable. More recently Carroll et al $^{12}$ postulated that these cells might possess endothelial cell receptors which are organ-specific.

If malignant angioendotheliosis is an intravascular lymphoma it may prove sensitive to chemotherapy and there have been a few reports of patients who were successfully treated with anti-leukaemic drugs. ${ }^{132223}$ In the absence of cutaneous involvement leptomeningeal or cerebral biopsy may be diagnostic. ${ }^{24}$

Further phenotypic characterisaton of the malignant lymphocyte and identification of its site of origin in this condition may lead to malignant angioendotheliosis becoming a treatable rather than an inevitably fatal disease.

We thank Dr R Abraham and Dr MA Newton for permission to report details of the patient, Professor PG Isaacson for many of the immunocytochemical stains and Miss K Anson for the photographs.

\section{References}

1 Pfleger L, Tappeiner J. Zur kenntnis der systemisierten endotheliomatose der cutanen blutgefasse (reticuloendotheliose?) Hautarzt 1959;10:359-63.

2 Bots GTAM. Angioendotheliomatosis of the central nervous system. Acta Neuropathol (Berl) 1974;28:75-8.

3 Petito CK, Gottlieb GJ, Dougherty JH, Petito FA. Neoplastic angioendotheliosis: ultrastructural study and review of the literature. Ann Neurol 1978;3:393-9.

4 Ojeda VJ. Neoplastic angioendotheliosis of the spinal cord. Case report. Acta Neuropathol (Berl) 1983;62:164-6.

5 Reinglass JL, Muller J, Wissman S, Wellman H. CNS angioendotheliosis. A treatable multiple infarct dementia. Stroke 1977;8:218-21.

6 Beal MF, Fisher CM. Neoplastic angioendotheliosis. J Neurol Sci 1982;53:359-75.

7 Wick MR, Banks PM, McDonald TJ. Angioendotheliomatosis of the nose with fatal systemic dissemination. Cancer 1981;48: 2510-7.

8 Kitagawa M, Matsubara O, Song S-Y, Kurashima C, Okeda R, Kasuga T. Neoplastic angioendotheliosis: immunohistochemical and electron microscopic findings in three cases. Cancer 1985;56:1134-43.

9 Dolman CL, Sweeney VP, Magil A. Neoplastic angioendotheliosis. The case of the missed primary? Arch Neurol 1979;36:5-7.

10 Wick MR, Mills SE, Scheithauer BW, Cooper PH, Davitz MA. Angioendotheliomatosis: an immunohistochemical reassessment. Lab Invest 1985;52:75A.

11 Beal MF, Ferry JA. Case records of the Massachusetts General Hospital. Case 39. N Engl J Med 1986;315:874-85.

12 Carroll TJ, Schelper RL, Goeken JA, Kemp JD. Neoplastic angioendotheliomatosis: immunopathologic and morphologic evidence for intravascular malignant lymphomatosis. Am J Clin Pathol 1986;85:169-75.

13 Sheibani K, Battifora H, Winberg CD, et al. Further evidence that "malignant angioendotheliomatosis" is an angiotropic large cell lymphoma. $N$ Engl J Med 1986;314:943-7.

14 Scott PWB, Silvers DN, Helwig EB. Proliferating angioendotheliomatosis. Arch Pathol Lab Med 1975;99:323-6.

15 Warnke RA, Gatter KC, Falini B, et al. Diagnosis of human lymphoma with monoclonal antileukocyte antibodies. $N$ Engl $J$ Med 1983;309:1275-81.

16 Mori S, Itoyama S, Mohri N, Shibuya A, et al. Cellular characteristics of neoplastic angioendotheliosis. An immunohistological marker study of 6 cases. Virchows Arch $(A)$ 1985;407:167-75.

17 Wrotnowski U, Mills SE, Cooper PH. Malignant angioendotheliomatosis. An angiotropic lymphoma? Am J Clin Pathol 1985;83:244-8.

18 Braverman IM, Lerner AB. Diffuse malignant proliferation of vascular endothelium. Arch Dermatol 1961;84:22-30.

19 Ansell J, Bhawan J, Cohen S, Sullivan J, Sherman D. Histiocytic lymphoma and malignant angioendotheliomatosis: one disease or two. Cancer 1982;50:1506-12.

20 Bhawan J, Wolff SM, Ucci AA, Bhan AK. Malignant lymphoma and malignant angioendotheliomatosis: one disease. Cancer 1985;55:570-6.

21 Hughes JT. Pathology of the Spinal Cord. 2nd edn. London: Lloyd-Luke, 1978:61-90.

22 Keahey TM, Guerry DIV, Tuthill RJ, Bondi EE. Malignant angioendotheliomatosis proliferans treated with doxorubicin. Arch Dermatol 1982;118:512-4.

23 Shiozaki H, Hoshino S, Oshimi K, et al. A case report of neoplastic angioendotheliosis which responded to a combination chemotherapy (CHOP). Nippon Naika Gakkai Zasshi 1983;73:374-8.

24 Ansbacher L, Low N, Beck D, Boarini D, Jacoby C, Cancilla PA. Neoplastic angioendotheliosis: a clinicopathological entity with multifocal presentation. $J$ Neurosurg 1981;54:412-5. 